\title{
The Teaching of Social Skills in Physical Education: Purposeful or Incidental?
}

\section{HRONIQUE • Point de vue internationale}

Students' social behaviors and interactions have been valued and incorporated in two out of five national standards of the Society of Health and Physical Educations in the United States, (SHAPE America, 2014). SHAPE America standards across kindergarten and twelve grades define what students should know and be able to do as a result of their participation in quality physical education programs. Ideally, the implementation of social skills into school curriculum targets student's achievement of responsible personal and social behavior that respects self and others (SHAPE America, Standard 4), in addition to, student's recognition of the value of physical activity for health, enjoyment, challenge, self-expression and/or social interaction (SHAPE America, Standard 5). However, in reality, studies have shown that social skills are perceived as automatic outcomes of students' participation in games and group activities, and it is rarely infused into the curriculum (Ward, \& Vidoni, 2009). Instead, social skills are incidentally taught, and often associated to punishment or reprimands of students' misconducts during lessons (Ward, 2006).

\section{Social Skills: Desirable Context-Specific Behaviors}

Social skills can be defined as an individual's learned behaviors, within a given context, that fosters the likelihood of producing, maintaining, or enhancing positive effects for the individual (Ward, 2006). Since social skills are context-specific, it is critical to consider that students come to class with a different repertoire of skills. This means that some students already developed social 
skills in another physical education or physical activity setting. These students may consistently or occasionally display these behaviors. Other students, who have a different learning history, may not possess desirable social skills for physical education classes. Based on these considerations, the literature in physical education implies that social skills may remain underdeveloped unless teachers implement strategies to explicitly teach context-specific social behaviors (Ward, 2006). In order to change this scenario, teachers need to set up the learning environment to explicitly teach, reinforce performance of social behaviors, and provide opportunities for students to practice during lessons (Vidoni \& Ward, 2009).

\section{Targeting Social Behaviors}

Students' behaviors directly influence teacher's selection of what behaviors should be taught and reinforced during lessons. In order to help students develop social skills and achieve social goals in physical education, teachers need to keep in mind different levels of social skills. A simple way to address this is to imagine a continuum (see Figure 1) that would depict the transition from 'lack of social skills', to 'compliance with class rules,' and would progress toward 'prosocial behaviors.'

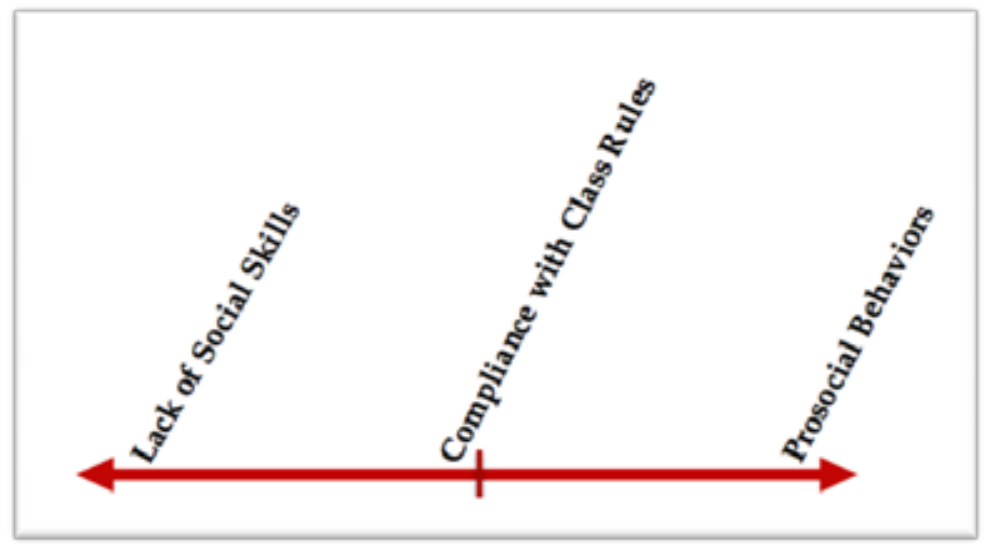

Figure 1. Continuum Between Levels of Social Skills

Examples of levels of social skills are: (a) lack of social skills: students who behave inappropriately or misbehave are likely to insult or offend teammates and others, disrespect officials, blame others for their own faults, and are not responsible for class tasks (Siedentop et al., 2011), (b) compliance with class rules: students under self-control are those who are able to control their temper, and participate without disrupting the flow of the lesson (Hellison, 2011), and (c) prosocial behaviors: students go beyond compliance level are those who support each other's performance, show respect to opposing teams and officials, accept losses without complaint, and victory without gloating, and are responsible for the accomplishment of tasks (Ward, 2006). 


\section{Fair Play Instruction: A Teaching Strategy}

Fair Play Instruction is teaching strategy that consists of several components: (a) teacher's explanation of fair play behaviors, (b) students' selection of fair play behaviors that need to be displayed more often, (c) a chart posted on the wall with a list of behaviors that students are willing to perform more often, (d) teacher prompts during the lesson to remind students about the behaviors they chose to perform, and (e) positive pinpointing from students and teacher during lesson closure.

Explanation of fair play behaviors. The teacher observes students' social behaviors during several lessons, and selects the ones or lack thereof that can be changed or developed during classes. The teacher then explains to the students that some behaviors are aggressive or inadequate for the class, and/or some positive ones are not being performed. The teacher asks students to show examples and give demonstrations of fair play behaviors that can replace negative ones, and/or ask for examples and demonstrations of positive behaviors that are not observed in the lesson.

Students' selections of fair play behaviors. In small or large groups, the teacher asks students to discuss fair play behaviors that they think are needed and they are willing to perform during the lessons.

Chart on the wall. The teacher asks students to write down on a blank chart three or four behaviors they think are more important for the next few lessons. The chart remains posted on the wall until the teacher chooses to remove it or to change the list of behaviors.

Prompts. The teacher chooses instances during the lesson to remind students about the behaviors they chose to display in a determined situation.

Pinpointing. During lesson closure, the teacher pinpoints and also asks students to pinpoint fair play behaviors they notice during the class.

\section{Conclusion}

Fair Play Instruction is an example of an intervention that was successfully implemented in two research studies. The studies showed that this strategy does not take much time from instruction. The first day, or days when students work on the chart, requires more time and elaboration. Subsequent days are based on teacher's prompts to maintain performance of behaviors, and a brief closure with pinpointing and feedback to reinforce behaviors. More importantly, this strategy provides an example on how teachers can purposefully, instead of incidentally set up the environment to teach, reinforce and maintain social behaviors. 


\section{References}

Hellison, D. (2011). Teaching responsibility through physical activity. Champaign, IL: Human Kinetics.

SHAPE America - Society of Health \& Physical Education (2014). National Standards E

Grade-Level Outcomes for K-12 Physical Education. Champaign, IL: Human Kinetics.

Siedentop, D., Hastie, P., \& van der Mars, H. (2011). Complete guide to Sport Education. Champaign, IL: Human Kinetics.

Vidoni C., \& Ward P. (2009) Effects of fair play instruction on student social skills

during a middle school sport education unit. Physical Education and Sport Pedagogy, 14, 285-310.

Ward, P. (2006). The philosophy, science, and application of behavior analysis in physical education. In D. Kirk., D.

Macdonald, \& M. O'Sullivan The Handbook of Physical Education (pp. 3-21). Sage Publications.

\section{Pour citer cet article}

Vidoni, C. (2016). The Teaching of Social Skills in Physical Education: Purposeful or Incidental? Formation et profession. 24(3), 90-93. http://dx.doi.org/10.18162/fp.2016.a106 